\title{
Indicadores salivares e o risco de cárie na Síndrome de Down utilizando o software Cariogram ${ }^{\circledR}$
}

\author{
Salivary indicators and the caries risk in Down Syndrome using Cariogram software
}

\section{Rafael Celestino de Souza}

Professor Doutor do Curso de Pós-Graduação em Odontopediatria e Pacientes com Necessidades Especiais da Faculdade São Leopoldo Mandic

\section{Elcio Magdalena Giovani}

Professor Doutor

Coordenador do Curso de Odontologia da Universidade Paulista

\section{Resumo}

O objetivo deste estudo foi analisar o risco de cárie em indivíduos com Síndrome de Down (SD) utilizando o Software Cariogram $\odot$, associando aos indicadores salivares. Participaram do estudo 124 pacientes, entre 6-52 anos, 62 indivíduos SD e 62 indivíduos controles sem a sindrome. Foram recolhidos dados sobre dieta, uso de flúor, pH salivar, capacidade tampão e contagem de Streptococcus mutans. Os resultados mostraram que os indivíduos SD apresentaram maior índice de placa, capacidade tampão e fluxo salivar reduzidos. A hipossalivação mostrou uma associação moderada com índice CPOD e índice de placa. $\mathrm{Na}$ análise Cariogram ${ }^{\circledR}$ verificou-se alto risco de cárie nestes pacientes, e dada a importância e facilidade deste método de diagnóstico, sugerimos que seu uso seja ampliado como uma ferramenta importante para facilitar o controle da cárie em indivíduos SD.

Palavras-chave: cárie; saliva; Síndrome de Down; Streptococcus mutans.

\section{Abstract}

The aim of this study was to analyze the caries risk in Down Syndrome individuals (SD) using the Cariogram $\otimes$ software and salivary parameters. We considered a sample of 124 patients aged 6-52 years, 62 with SD and 62 without the syndrome (controls). Data were also collected on diet, use of fluoride, saliva $\mathrm{pH}$, buffer capacity and Streptococcus mutans count. The results were that the SD patients had a higher plaque index, lower buffering capacity and reduced salivary flow. A higher prevalence of hyposalivation, showing a moderate association with DMFT and plaque index. In the Cariogram ${ }^{\circledR}$ analysis we found a high risk of caries in these patients, and given the importance and ease of this method of diagnosis, we suggest that its use be established as an important tool in facilitating the control of caries in Down syndrome individuals.

Keywords: caries; saliva; Down syndrome; Streptococcus mutans.

\section{Introdução}

$\mathbf{A}$ Síndrome de Down (SD) ou trissomia do cromossomo 21 é o distúrbio cromossômico mais comum, apresentando deficiências, desarmonias e atraso de desenvolvimento em relação aos indivíduos sem a síndrome. O sistema imunológico destes indivíduos é afetado profundamente, tanto na sua resposta inata e adaptativa, produzindo uma maior susceptibilidade às infecções (1-3). Os acometimentos bucais mais prevalentes na SD são: boca aberta permanente, fissura labial, protrusão da língua, língua hipotônica e fissurada, palato alto e anomalias dentais $(4,5)$. Estas, frequentemente, desenvolvem doença periodontal severa e um risco de cárie contraditório, justificado pela alteração imunológica, higienização bucal e comprometimento intelectual e na coordenação motora (2-7).

A prevalência e a incidência dessas doenças estão associadas ao nível de desenvolvimento e políticas públicas de saúde bucal. Em relação à cárie dentária, o curso da doença e seus riscos dependem de diversos fatores como a microbiota bucal, aspectos comportamentais e individuais e também das patologias de base nesses de pacientes (8-11).

A avaliação do risco de cárie é importante para predizer se um indivíduo desenvolverá lesões durante um período específico de tempo, principalmente quando o mesmo possui algum tipo de necessidade especial. Essa avaliação é importante para obtenção do conhecimento precoce da doença, para que se possa instituir condutas preventivas, escolher adequadamente o tratamento a ser executado, otimizando os recursos disponíveis para estudos epidemiológicos (11-12).

Inúmeras pesquisas apontam que os indicadores salivares na SD (14-19) apresentam diversas alterações em sua composição e efeito na cavidade oral, porém a grande maioria delas foi realizada em crianças ou adolescentes, dificilmente abrangendo a faixa etária da $3^{\mathrm{a}}$ até $5^{\mathrm{a}}$ década de vida. Estas alterações em saliva podem acarretar aumento do risco de cáries destes indivíduos, principalmente, quando analisamos uma população adulta (17).

Gao et al. (2010), ao propor a construção de um modelo para avaliação do risco de cárie em crianças, constataram que não existem modelos práticos estabelecidos na literatura, porém, são urgentemente necessários para um efetivo controle de cárie. Ainda, sugerem uma intervenção com modelos biopsicossociais que incluem, questionário oral, avaliação clínica (experiência de cáries e higiene oral), ensaios biológicos (salivares, microbiológicos e $\mathrm{pH}$ de placa), afirmando que estes modelos são ferramentas promissoras no controle da cárie e tratamento baseado em evidências de planejamento.

Com intenção de explicar ao paciente a natureza da cárie de maneira simples e compreensível, foi desenvolvido por Bratthall, em 1997, o Cariograma ${ }^{\circ}$, um programa de computador que ilustra o risco que o paciente apresenta de desenvolver cárie. Recentemente, o programa vem ganhando notoriedade e crédito na comunidade científica, com o lançamento da versão computadorizada e repercussões em pesquisas. O programa foi criado com base na tradicional tríade de Keyes (1962) e além de traçar a possibilidade de desenvolvimento de cárie, recomenda medidas específicas, de acordo com as necessidades individuais $(20,21)$. 
A presente pesquisa propõe-se a analisar os indicadores salivares, como: $\mathrm{pH}$, capacidade tampão, fluxo salivar e a presença de Streptococcus mutans (quantitativo) em saliva total de indivíduos com Síndrome de Down utilizando o programa Cariograma e associando-os com os riscos de cárie.

\section{Material e Métodos}

A presente pesquisa constituiu-se de 124 indivíduos, sendo Grupo I - 62 com diagnóstico médico de Síndrome de Down comprovado através do cariótipo e Grupo II - 62 indivíduos controle sem a diagnóstico de Síndrome de Down, de ambos os gêneros, com idade variando entre 6 e 52 anos. $\mathrm{O}$ atendimento destes pacientes foi realizado no CEAPE (Centro de Estudos e Atendimento a Pacientes Especiais) da Faculdade de Odontologia da Universidade Paulista do Campus Indianópolis (UNIP-SP) e teve início após a aprovação pelo CEP-UNIP 393/10.

Em ambos os grupos foi realizada a anamnese com os pacientes e responsáveis e, em seguida, para o Grupo I, foram procedidas sessões de dessensibilização para poder criar vínculo com o paciente e facilitando o tratamento e evitando stress e trauma para o mesmo. Os dados coletados foram: tipo de comprometimento genético, história dental pregressa, uso de medicamentos, atividade de vida diária, diário alimentar e institucionalização. Também foi avaliado o número de escovações diárias, quem realiza a higiene bucal e o uso de flúor. Então se iniciava o exame físico, avaliando o índice de placa, índice de CPO e a coleta salivar.

\section{- Dieta}

A avaliação dos hábitos alimentares foi obtida através de preenchimento do diário alimentar pelos participantes e responsáveis. Foram atribuídos escores para o conteúdo de açúcar na dieta, sendo 0 , muito pouco consumo - dieta balanceada; 1, baixo consumo - dieta não cariogênica; 2 , consumo moderado - dieta ainda não cariogênica; 3 , alto consumo - dieta cariogênica. E em relação à frequência de consumo de açúcar, sendo 0 , consumo máximo de 3 vezes/dia; 1 , consumo máximo de 5 vezes/dia; 2, consumo máximo de 7 vezes/dia e 3, consumo máximo superior a 7 vezes/dia.

\section{- Coleta Salivar}

A coleta salivar foi realizada em jejum por um período mínimo de 2 horas, preconizado o período da manhã, evitando a influência do ritmo circadiano, estando os mesmos posicionados sentados e relaxados. A saliva total dos indivíduos foi coletada por estímulos mecânicos, através da mastigação de um pedaço de parafina medindo $10 \mathrm{~cm} \mathrm{X} 10 \mathrm{~cm}$ e pesando, aproximadamente 1,4 gramas, disponível no kit Dentobuff (Figura 1). Toda a saliva produzida nos primeiros trinta segundos era desprezada (deglutida ou expelida), em seguida se iniciava a coleta por exatamente cinco minutos. Durante toda a cronometragem o indivíduo continuava mastigando e expelindo a saliva em um Becker de vidro graduado. Nos indivíduos que apresentavam dificuldade na realização do teste devido à falta de maturidade intelectual para mascar a goma e não engolir, ou dificuldade para cuspir a saliva, se utilizava roletes de algodão amarrados a um fio dental, que eram introduzidos na boca, e trocados quando imersos por saliva, durante 5 minutos. A saliva colhida através dos roletes de algodão foi pesada em balança análica e, após aferido o fluxo salivar, foi extraída para um Becker de vidro graduado pertencente ao Kit Dentobuff ${ }^{\oplus}(5)$.

\section{- Fluxo Salivar/Velocidade de Secreção}

O fluxo salivar foi determinado pela relação entre o volume coletado pelo tempo de 5 minutos. A velocidade de secreção salivar foi demonstrada em mililitros por minuto $(\mathrm{ml} / \mathrm{min})$. O volume salivar foi dividido pelo tempo de coleta e interpretado segundo o fabricante, sendo normal entre 1,6 e 2,3 ml/min, intermediário (moderado) entre 1,0 e 1,5 ml/min, baixo ou severo quando menor que $1,0 \mathrm{ml} / \mathrm{min}$.

\section{- pH e Capacidade Tampão}

$\mathrm{O}$ pH salivar e a capacidade tampão foram mensurados utilizando-se o kit Dentobuff ${ }^{\oplus}$ e Dentobuff Strip ${ }^{\circledR}$, em método colorimétrico, tendo utilizado a saliva coletada para mensuração do fluxo salivar. Foi adicionado $1,0 \mathrm{ml}$ de saliva a um flaconete contendo $3 \mathrm{ml}$ de HCL (ácido clorídrico) a 0,005\%. Dos indivíduos cuja coleta salivar for inferior a 1,0 ml o exame era realizado com a quantidade de saliva disponível no copo graduado. Foram adicionadas também quatro gotas do indicador, disponível no kit e de acordo com o fabricante, feito isso o flaconete foi devidamente tampado e agitou-se a mistura por 10 segundos. Então se realizou a análise, comparando com a escala colorimétrica pertencente ao kit, obtendo-se o resultado do $\mathrm{pH}$ salivar (5).

\section{- Contagem de Streptococcus mutans na Saliva}

A saliva foi inoculada com uma pipeta no meio ágar Mitis Salivarius modificado, do kit Dentalcult II $^{\circledR}$ (Figura 2) e incubada em estufa bacteriológica a $37^{\circ} \mathrm{C}$, sob tensão de $\mathrm{CO}$ durante $24-48 \mathrm{~h}$ e 2 com discos de bacitracina aderidos à superfície do meio para propiciar o desenvolvimento de Streptococcus mutans, se presente no material. Após a incubação, foi analisado o crescimento e realizada a leitura da contagem de colônias (Figura 3) através da comparação visual com o gabarito de comparação, fornecido pelo fabricante. 


\section{- Software Cariograma®}

Os dados obtidos para cada paciente foram aplicados no programa de computador Cariograma 1.0 para Windows (Faculdade de Odontologia, Malmö, Suécia) $(20,21)$. Neste, foi inserida a identificação do paciente e a seguir foram completados os campos existentes com as avaliações clínicas, salivares e microbiológicas. O programa apresentava os resultados em forma de percentuais, construindo um risco de cárie individual (Figura 4).

\section{- Análise Estatística}

Foram utilizadas as análises estatísticas do teste $\mathrm{t}$ de Student, teste qui-quadrado de homogeneidade tradicional e teste qui-quadrado exato. Em todos os testes foi considerado um nível de significância de 5\%.

\section{Resultados}

As amostras possuem um número pareado de pacientes nos Grupos I e II e entre eles não há diferenças estatísticas significantes quanto ao gênero, raça e idade. $\mathrm{Na}$ análise, subdividiu-se a faixa etária em três grupos: 0 a 12 anos (40,3\%), 13 a 18 anos (29,0\%) e 19 a 52 (30,7\%). As mulheres representavam 51,6\% do grupo II e 35,5\% do grupo I. Em ambos os grupos, a maioria dos pacientes eram leucodermas (71,0\% no grupo II e $83,9 \%$ no grupo I).

Na tabela I observa-se que o grupo I apresenta, em média, maior índice de placa ( $\mathrm{p}=0,0009)$ e no entanto, não há indícios de que a média do CPO varia de acordo com o grupo $(\mathrm{p}=0,1201)$. Notar que o grupo I apresenta menor capacidade tampão $(\mathrm{p}<0,0001)$ e menor fluxo salivar $(\mathrm{p}<0,0001)$ e no entanto, não há indícios de que a média do PH $(\mathrm{p}=0,2623)$ e da contagem de Streptococcus mutans $(\mathrm{p}=0,7681$ ) varia de acordo com o grupo. A Tabela II mostra a distribuição de frequência entre as variáveis comuns para o risco de cárie por a análise de software e Cariogram ${ }^{\oplus}$ o valor de p da comparação da distribuição do risco de cárie em três subgrupos para faixa etária.

A hipossalivação (Tabela III) foi mais elevada no grupo SD $(83,9 \%)$ do que no grupo de controlo $(22,6 \%)$ e estatisticamente significativo $(\mathrm{p}<0,0001)$. A Tabela IV apresenta os resultados dos indicadores salivares associados com o índice de $\mathrm{CPO}$ e índice de placa. Observamos que, no grupo controle, há uma associação negativa moderada entre pH e CPOD e também entre capacidade tampão e índice de placa. No grupo SD foi encontrado um aumento do fluxo salivar sugere uma diminuição do CPOD e do índice de placa. Há ainda fraca associação negativa entre a capacidade tampão e CPO-D.

Tabela I. Média, desvio padrão e valor p para as variáveis de CPO, índice de placa e indicadores salivares

\begin{tabular}{|c|c|c|c|c|}
\hline Variável & Grupo & Média & D.P. & $\mathbf{P}$ \\
\hline CPO & $\begin{array}{c}\text { Controle } \\
\text { SD }\end{array}$ & $\begin{array}{l}3,9 \\
5,1\end{array}$ & $\begin{array}{l}4,1 \\
4,2\end{array}$ & 0,1201 \\
\hline Índice de Placa & $\begin{array}{c}\text { Controle } \\
\text { SD }\end{array}$ & $\begin{array}{l}37,6 \\
54,6\end{array}$ & $\begin{array}{l}23,2 \\
32,1\end{array}$ & 0,0009 \\
\hline $\mathrm{pH}$ & $\begin{array}{c}\text { Controle } \\
\text { SD }\end{array}$ & $\begin{array}{l}6,5 \\
6,3\end{array}$ & $\begin{array}{l}0,6 \\
0,8\end{array}$ & 0,2623 \\
\hline Capacidade Tampão & $\begin{array}{c}\text { Controle } \\
\text { SD }\end{array}$ & $\begin{array}{l}6,2 \\
5,2\end{array}$ & $\begin{array}{l}0,9 \\
1,2\end{array}$ & $<0,0001$ \\
\hline Fluxo Salivar & $\begin{array}{c}\text { Controle } \\
\text { SD }\end{array}$ & $\begin{array}{l}1,5 \\
0,5\end{array}$ & $\begin{array}{l}0,4 \\
0,5\end{array}$ & $<0,0001$ \\
\hline Contagem de SM & $\begin{array}{c}\text { Controle } \\
\text { SD }\end{array}$ & $\begin{array}{l}2,7 \\
2,6\end{array}$ & $\begin{array}{l}1,1 \\
1,3\end{array}$ & 0,7681 \\
\hline
\end{tabular}


Tabela II. Distribuição de frequências conjuntas absoluta e relativa entre as variáveis risco de cárie pela análise Cariograma ${ }^{\circledR}$ e Idade para o grupo SD e Control

\begin{tabular}{|c|c|c|c|c|c|c|c|c|}
\hline \multirow{2}{*}{$\begin{array}{c}\text { Risco } \\
\text { de } \\
\text { Cárie }\end{array}$} & \multicolumn{2}{|c|}{0 a 12} & \multicolumn{2}{|c|}{13 a 18} & \multicolumn{2}{|c|}{19 ou mais } & \multicolumn{2}{|c|}{ Total } \\
\hline & Controle & SD & Controle & SD & Controle & SD & Controle & SD \\
\hline $\begin{array}{l}\text { Baixo } \\
\text { Relativ. }\end{array}$ & $4(15,4)$ & $2(8,3)$ & $0(0,0)$ & $4(20,0)$ & $2(10,0)$ & $2(11,1)$ & $6(9,7)$ & $8(12,9)$ \\
\hline Baixo & $12(46,2)$ & $8(33,3)$ & $10(62,5)$ & $2(10,0)$ & $2(10,0)$ & $2(11,1)$ & $24(38,7)$ & $12(19,4)$ \\
\hline Intermediário & $6(23,1)$ & $2(8,3)$ & $4(25,0)$ & $4(20,0)$ & $2(10,0)$ & $0(0,0)$ & $12(19,4)$ & $6(9,7)$ \\
\hline Alto & $4(15,4)$ & $2(8,3)$ & $2(12,5)$ & $4(20,0)$ & $6(30,0)$ & $2(11,1)$ & $12(19,4)$ & $8(12,9)$ \\
\hline Muito Alto & $0(0,0)$ & $10(41,7)$ & $0(0,0)$ & $6(30,0)$ & $8(40,0)$ & $12(66,7)$ & $8(12,9)$ & $28(45,2)$ \\
\hline Total & $26(100,0)$ & $4(100,0)$ & $16(100,0)$ & $20(100,0)$ & $20(100,0)$ & $18(100,0)$ & $62(100,0)$ & $2(100,0)$ \\
\hline Controle & $P=0$ & 01 & SD & $P=0, C$ & & & & \\
\hline
\end{tabular}

Tabela III. Distribuição de frequências conjuntas absoluta e relativa para hipossalivação para o grupo SD e Controle

\begin{tabular}{|c|c|c|c|}
\hline \multicolumn{4}{|c|}{ Hipossalivação } \\
\hline Grupo & Não & Sim & Total \\
\hline Controle & $48(77,4)$ & $14(22,6)$ & $62(100,0)$ \\
\hline SD & $10(16,1)$ & $52(83,9)$ & $62(100,0)$ \\
\hline Total & & & $124(100,00)$ \\
\hline $\mathbf{P =}=0,0001$ & $58(46,8)$ & $66(53,2)$ & \\
\hline
\end{tabular}

Tabela IV. Correlação de Spearman entre as variáveis de indicadores salivares, o índice de placa e CPO

\begin{tabular}{|c|c|c|c|c|c|c|c|c|}
\hline \multirow{2}{*}{ Variável } & \multicolumn{4}{|c|}{ CPO } & \multicolumn{4}{c|}{ Índice de Placa } \\
\cline { 2 - 9 } & \multicolumn{2}{|c|}{ Controle } & SD & Controle & SD \\
\cline { 2 - 10 } & Correlação & $\boldsymbol{P}$ & Correlação & $\boldsymbol{P}$ & Correlação & $\boldsymbol{P}$ & Correlação & $\boldsymbol{P}$ \\
\hline pH & $-0,48223$ & $<0,0001$ & 0,02296 & 0,8594 & $-0,26834$ & 0,0382 & 0,06172 & 0,6337 \\
\hline Capacidade Tampão & $-0,02232$ & 0,8656 & $-0,35161$ & 0,0051 & $-0,55951$ & $<0,0001$ & $-0,23649$ & 0,0642 \\
\hline Fluxo Salivar & $-0,09603$ & 0,4655 & $-0,42215$ & 0,0006 & $-0,22556$ & 0,0831 & $-0,45405$ & 0,0002 \\
\hline Contagem de SM & 0,42193 & 0,0006 & 0,16525 & 0,1993 & 0,30958 & 0,0143 & 0,18788 & 0,1437 \\
\hline
\end{tabular}

\section{Discussão}

Pacientes com SD geralmente possuem uma higienização bucal deficitária, que tende a piorar com a idade e, como consequência, evidencia outras complicações bucais. Embora a literatura não seja concisa ao abordar a incidência de cárie em 
$\mathrm{SD}$, muitos estudos apontam uma baixa prevalência de cárie $(4,19)$, enquanto outros revelam que a precária higiene e alteração nos indicadores salivares promovem alto índice de cárie $(13,15,22,23)$. Recentemente, uma revisão sistemática conduzida por Moreira et al. (2016) revelaram que não há evidencia científica para apoiar a hipótese de que as pessoas com síndrome de Down têm uma experiência de baixa de cárie do que os indivíduos não sindrômicas. Em nosso estudo, notou-se que o grupo SD apresenta, em média, maior índice de placa $(\mathrm{p}=0,0009)$, com maior índice de CPO médio, porém, não significativo em relação ao grupo controle ( $\mathrm{p}=0,1201)$, concordando com os achados de Yarat et al. (1999) e Siqueira et al. (2007), que constataram que o índice de cáries não diferia do grupo controle, mesmo com o fluxo salivar acentuadamente baixo.

Em outros pontos de vista, a alta prevalência de CPOD no grupo SD pode ter sido influenciada pela faixa etária, porque a maioria dos estudos que avaliam a experiência de cárie na síndrome de Down analisam principalmente crianças. O nosso estudo também incluiu adolescentes e adultos e isso pode explicar os resultados obtidos. Uma vez que os indivíduos têm maior tempo de exposição na cavidade bucal a fatores predisponentes que fazem parte do desenvolvimento de cárie.

Em relação aos indicadores salivares, nosso estudo observou que o grupo SD apresenta menor fluxo salivar, menor capacidade tampão do que o grupo controle, conhecimento este já solidificado na literatura. Embora, este estudo contemplou somente uma forma de análise na aferição do $\mathrm{pH}$ e fluxo salivar, outros estudos com diferentes metodologias encontraram resultados similares $(13,16-18)$.

Os valores para velocidade do fluxo salivar apontam que há existência de uma alteração na função secretora das glândulas salivares dos indivíduos com SD, como observado por Siqueira et al. (2004). Estes resultados são notados em todas as faixas etárias e gêneros, um achado não relatado em outros estudos. Há indícios de que esta redução pode ter sido em parte causada pela influência que a própria síndrome exerce sobre a função nas glândulas salivares e pela hipotonia muscular, anomalia muito comum nos indivíduos SD (3). Desta alteração, pode sugerir uma redução no clearance salivar, o qual é diretamente dependente do fluxo salivar, sendo maior nos indivíduos com um fluxo salivar regular e menor naqueles indivíduos que apresentam baixo fluxo, podendo assim, aumentar os riscos de doenças orais nesses indivíduos (17).

O fluxo salivar diminuído sugere um risco aumentado de cáries, sabendo que a saliva desempenha um papel essencial no equilíbrio da cavidade oral, executar a limpeza e remoção de restos de alimentos e bactérias $(14,20)$, o que poderia influenciar o alto índice de cárie foram observados em indivíduos deste estudo.

Ainda em relação aos indicadores salivares, nosso estudo avaliou que a capacidade tampão foi significantemente menor no grupo SD, com média de 5,2, discordando com
Siqueira (2004), que encontrou em seu estudo uma capacidade tampão salivar aumentada nos indivíduos com SD. Essa diferença pode ter ocorrido porque os pacientes não estão na mesma faixa etária. Siqueira et al. estudaram um grupo pediátrico e nosso estudo abrangeu uma faixa etária maior (6-52 anos). Alguns outros estudos diagnosticaram a capacidade tampão na saliva não estimulada em SD similares a indivíduos sem a síndrome (21).

A capacidade tampão não mostrou relação com o índice CPO-D, uma vez que por ser baixa no grupo SD poderia ser uma explicação para a elevada prevalência de CPO-D. Os parâmetros salivares estudados fornecem achados que foram medidos a partir da metodologia aplicada, o que pode explicar a diferença quando comparado a outros estudos, especialmente os mais antigos. A metodologia escolhida está consagrada na literatura e fácil de usar e aplicável a pacientes com deficiências intelectuais $(5,6,13,14)$.

No presente estudo, não há indícios de que a média do $\mathrm{pH}(\mathrm{p}=0,2623)$ e da contagem de Streptococcus mutanss ( $\mathrm{p}$ $=0,7681$ ) varia de acordo com o grupo. Na literatura existem dados conflitantes de $\mathrm{pH}$ em relação a SD, em que valores superiores de $\mathrm{pH}$ salivar foram relatados $(29,30)$, valores inferiores (19) ou ainda não observam nenhuma diferença nessa população quando comparada com indivíduos sem a síndrome $(11,18,21)$. Alguns fatores como método de coleta, método de mensuração, idade dos indivíduos, localização geográfica e alimentação poderiam influenciar os resultados descritos na literatura.

Em relação à contagem de Streptococcus mutans salivar, o valor médio foi similar ao grupo controle. Este achado vai de encontro aos estudos de Areias et al. (2012) e Castilho et al. (2011), que encontraram valores sem diferença estatística em relação aos indivíduos sem a síndrome.

Em relação à associação das variáveis de indicadores salivares com o CPO e com o índice de placa, como mostrado na tabela II, pode-se notar que no grupo controle houve uma associação negativa moderada entre pH e CPO (correlação $=-0,48, \mathrm{p}<0,0001)$ e entre capacidade tampão e índice de placa (correlação $=-0,56, p<0,0001$ ). Dessa forma, em geral, quanto maior o valor do $\mathrm{pH}$ menor tende a ser o CPO e quanto maior o valor da capacidade tampão menor tende a ser o índice de placa.

Estes resultados foram usados para justificar pesquisas sobre parâmetros salivares em crianças com $\mathrm{SD}$ em vários estudos, no entanto, é escassa a literatura sobre o risco de cárie em todas as faixas etárias de indivíduos com SD.

Conclui-se também que há uma associação positiva moderada entre contagem de Streptococcus mutans e CPO (correlação $=0,42, \mathrm{p}=0,0006)$. Shapira et al., 1991, não encontraram relação entre CPO e a contagem de SStreptococcus mutans. Detectou-se ainda associação negativa fraca entre pH e índice de placa (correlação $=-0,27, \mathrm{p}=0,0382$ ) e uma associação positiva fraca entre contagem de Streptococcus mutans e índice de placa (correlação $=0,31, \mathrm{p}=0,0143$ ). Porém no grupo com $\mathrm{SD}$, foi possível identificar quatro pares 
de associações entre as variáveis de interesse, sendo que quanto maior o fluxo salivar menor tende a ser o CPO (correlação = $-0,42, p=0,0006)$ e o índice de placa (correlação $=-0,45, p=0,0002$ ) e há ainda associação negativa fraca entre a capacidade tampão e o CPO (correlação $=-0,35, \mathrm{p}=0,0051$ ). Com este resultado, podemos definir um perfil para o risco de cárie na Síndrome de Down como relacionado a parâmetros salivares, contrastando com aqueles sem a síndrome.

Nossa pesquisa também analisou o risco de cárie pelo software Cariograma ${ }^{\circledR}$ de acordo com Gao et al. (2010), o programa tem sensibilidade moderada (71\%) e especificidade (66\%). No grupo SD, não há nenhuma evidência de que a distribuição do risco de cárie varia com a idade ( $\mathrm{p}=0,0984)$, desta forma para todos os grupos etários, encontramos maior risco de cárie (41,7\% em crianças; $30 \%$ de adolescentes e $66,7 \%$ em adultos), diferente do grupo controle, em que $70 \%$ dos adultos tiveram uma alta risco ou muito alto risco de cárie, enquanto que entre crianças e adolescentes, apenas $15,4 \%$ e $12,5 \%$, respectivamente. Embora não haja nenhuma diferença estatisticamente significativa em relação ao índice de cárie entre os grupos, o alto risco de cárie concorda com as condições clínicas apresentadas e os parâmetros salivares de indivíduos com SD. Nós também descobrimos que indivíduos SD apresentaram uma associação positiva CPO-D e índice de placa com hipossalivação ( $\mathrm{p}<0,0001$ ). Estas conclusões estão em conformidade com Antonnacio et al. (2009), que encontraram prevalência de cárie mais elevados em indivíduos com SD e hipossalivação.

Uma grande limitação deste estudo são os diferentes métodos utilizados para a análise salivar. Tal desvantagem poderia ter um impacto significativo sobre o resultado do estudo, uma vez que dificulta a comparação com outros estudos. Devido ao pequeno tamanho da amostra, que é a principal limitação do nosso estudo, a robustez das nossas conclusões sobre subgrupos de idade nos resultados de cárie é limitada, e não fomos capazes de demonstrar diferenças mais significativas entre o SD e grupo controle. São necessários, portanto, as maiores estudos com subgrupos e amostras maiores para investigar as diferenças entre os gêneros e faixa etária.

No entanto, apesar da insuficiente força do estudo para permitir comparações entre os subgrupos, existe uma diferença estatisticamente significativa nos parâmetros salivares, que provavelmente indica um aumento do risco de cárie no grupo SD. Um risco de cárie alto foi estabelecido no grupo SD, e sugerimos a implementação de um programa preventivo que aborda as características únicas dos indivíduos SD e dá-lhes a atenção que eles precisam para evitar cáries futuras, promovendo assim a sua saúde geral e melhorando sua qualidade de vida.

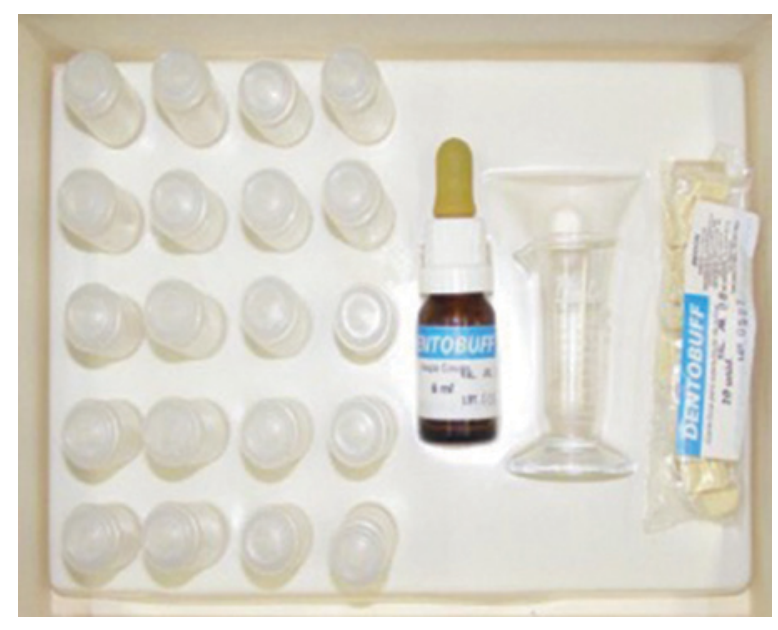

Figura 1. Constituição do kit DentoBuff®

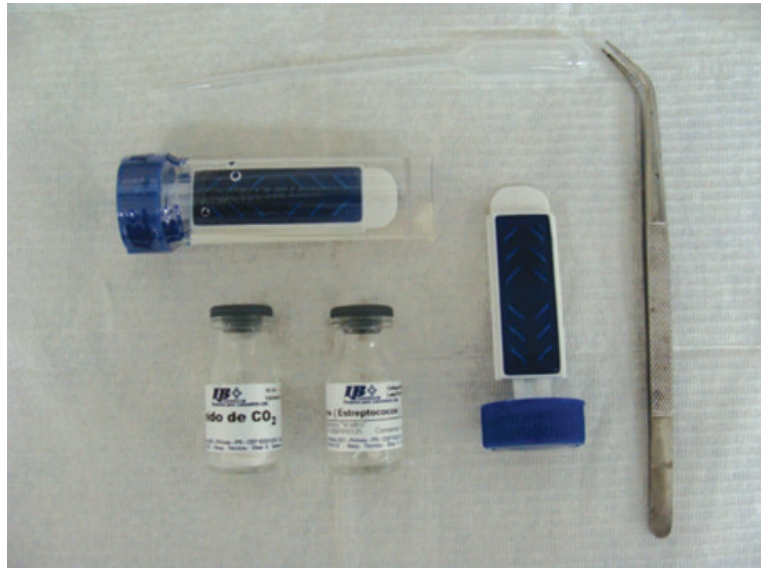

Figura 2. Esquema da mesa de trabalho do kit Dentalcult ${ }^{\circledR}$, laminocultivo para identificação e contagem de Streptococcus mutans 


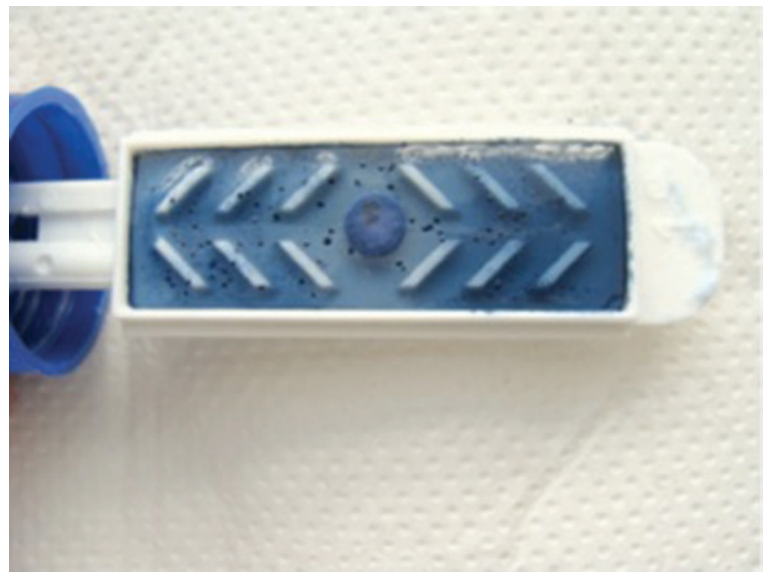

Figura 3. Laminocultivo Dentalcult ${ }^{\circledR}$ de um paciente expressando um resultado de 10-1 UFC/ml

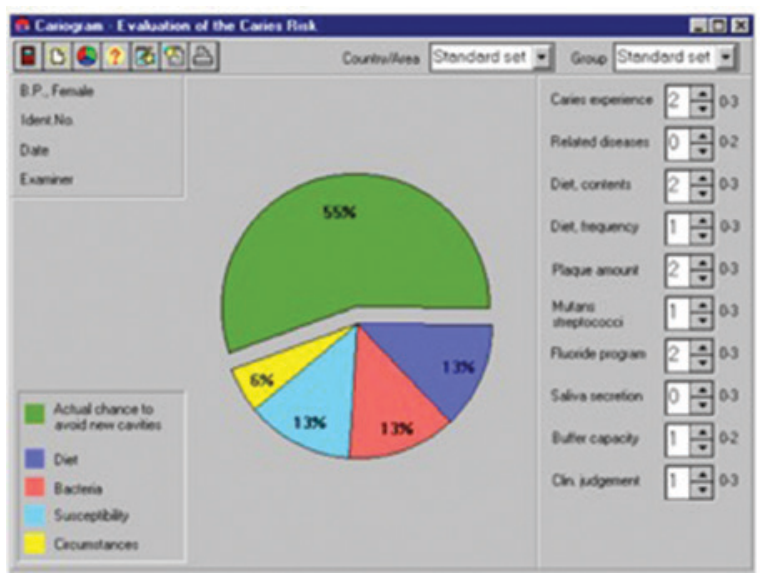

Figura 4. Exemplo do resultado da avaliação de risco de cárie de um paciente através do software Cariograma ${ }^{\circledR}$

\section{Conclusão}

O grupo SD apresentou maior índice de placa, menor capacidade tampão e menor fluxo salivar, maior prevalência de hipossalivação, evidenciando uma associação moderada com o CPO e com o índice de placa. Estes pacientes apresentaram através da análise do Cariograma ${ }^{\circledR}$ um risco de cárie alto, sendo que, frente à importância e facilidade desse método de diagnóstico, sugerimos que sua utilização seja instituída como uma ferramenta importante e facilitadora no controle de cárie dos pacientes com SD. 


\section{Referências ::}

1. Schwertner C, Moreira MJ, Faccini LS, Hashizume LN. Biochemical composition of the saliva and dental biofilm of children with Down syndrome. Int J Paediatr Dent. 2016;26(2):134-40.

2. Lopez-Perez R, Borges-Yanez SA, Jimenez-Garcia G, Maupome G. Oral hygiene, gingivitis and periodontitis in persons with Down syndrome. Special Care Dentistry. 2002;22:214-20.

3. Desai SS. Down Syndrome: a review of literature. Oral Surg Oral Med Oral Pathol Oral Radiol Endod. 1997;84(3):279-85.

4. Moraes LME, Moraes LC, Dotto NG, Dotto PP, Santos RNA. Dental anomalies in patients with down syndrome. Braz. Dent. Journal. 2007; (8)4:123-5.

5. Antonaccio R, Cavasin-Filho J, Andia-Merlin R, Giovani E. Influence of Instruction of Oral Hygiene to Down Syndrome Patients on the Prevalence of Gingivitis. Special Care in Dentistry. 2008; 28(4):169.

6. Linossier A, Valenzuela CY, Toledo H. Differences of the oral colonization by Streptococcus of the mutans group in children and adolescents with Down syndrome, mental retardation and normal controls. Med Oral Patol Oral Cir Bucal. 2008;13(9):E536-9.

7. Borges MF, Castilho ARF, Pereira CV. Influência da sacarose, lactose e glicose + frutose no potencial cariogênico de S. mutans: estudo in situ e in vitro. Rev. odonto ciênc. 2008;23(4):360-4.

8. Mattos-Graner RO, Corrêa MSNP, Latorre MRO, Peres RCR, Mayer MPA. Mutans streptococci oral colonization in 12-30-month-old Brazilian children over a one-year follow-up period. Journal of Public Health Dentistry. 2001:61(3):161-7.

9. Shapira J, Stabholz A, Schurr D, Sela M, Mann J. Carie levels, Streptococcus mutans counts, salivary $\mathrm{pH}$, and periodontal treatment needs of adult Down syndrome patients. Spec Care Dentist. 1991;11(6):248-51.

10. Arai PS, Camargo ALR, Jorge AOC, Rego MA. Avaliação do risco de cárie em crianças através de método convencional e do programa cariograma. J Bras Odontopediatr Odontol Bebê. 2003;6(32):317-24.

11. Gao Xl, Hsu CYS, Xu Y, Hwarng HB, Loh T, Koh D. Building Caries Risk Assessment Models for Children. JDR. 2010;89(6):637-43.

12. Sánchez-Pérez L, Golubov J, Irigoyen-Camacho ME, Moctezuma PA, Acosta-Gio E. Clinical, salivary, and bacterial markers for caries risk assessment in schoolchildren: a 4-year follow-up. International Journal of Paedia- tric Dentistry. 2009(19):186-92.

13. de Castilho AR, Pardi V, Pereira CV. Dental caries experience in relation to salivary findings and molecular identification of S. mutans and S. sobrinus in subjects with Down syndrome. Odontology. 2011;99(2):162-7.

14. Chaushu S, Becker A, Chaushu G, Shapira J. Stimulated parotid salivary flow rate in patients with Down syndrome. Spec Care Dentist. 2002a;22(1):41-4.

15. Areias C, Sampaio-Maia B, Pereira Mde L, Azevedo A, Melo P, Andrade $\mathrm{C}$, et al. Reduced salivary flow and colonization by mutans streptococci in children with Down syndrome. Clinics (São Paulo). 2012;67(9):1007-11.

16. Jara L, Ondarza A, Blanco R, Rivera L. Composition of the parotid saliva in Chilean children with Down's syndrome. Arch Biol Med Exp. 1991;24(1):57-60.

17. Siqueira WLOE, Mustacchi Z, Nicolau J. Electrolyte concentrantions in saliva of children age 6-10 years with Down syndrome. Oral Surg Oral Med Oral Pathol Oral Radio Endod. 2004,98:76-9.

18. Yarat A, Akyuz S, Koc L, Erdem H, Emekli N. Salivary sialic acid, protein, salivary flow rate, $\mathrm{pH}$, buffering capacity and caries indices in subjects with Down's syndrome. J Dent. 1999;27(2):115-8.

19. Lee SR, Kwon HK, Song KB, Choi YH. Dental caries and salivary immunoglobulin A in Down syndrome children. 2004;40(9):530-3.

20. Carounanidy U, Sathyanarayanan R. Dental caries: A complete changeover (Part II)- Changeover in the diagnosis and prognosis. J Conserv Dent. 2009;12:87-100.

21. Petersson Gh, Fure S, Bratthall D. Evaluation of a computer based caries risk assessment program in an elderly group of individuals. Acta Odontol Scand. 2003;61:164-71.

22. Oredugba FA. Use of oral health care services and oral findings in children with special needs in Lagos, Nigeria. Spec Care Dentist. 2006:26(2):59-65.

23. Moreira MJ, Schwertner C, Jardim JJ, Hashizume LN. Dental caries in individuals with Down syndrome: a systematic review. Int J Paediatr Dent. 2016;26(1):3-12.

24. Winer R, Feller R. Composition of Parotid and Submandibular Saliva and Serum in Down's syndrome. J Dent Res. 1972;51(2):449-54.

Recebido em: 01/12/2015 Aprovado em: 04/02/2016

Rafael Celestino Colombo de Souza

Rua Padre Leonardo, 259

São Paulo/SP, Brasil - CEP: 04602-007

E-mail: rafaelcsouza@usp.br 